\title{
Structure, Characteristics and Corrosion Behaviour of Gold Nanocoating Thin Film for Biomedical Applications
}

\author{
Haitham M. Wadullah ${ }^{a *}$ (1), Mohammed Hadi Ali ${ }^{b}$,Tariq Khalid Abdulrazzaq ${ }^{a}$ \\ ${ }^{a}$ Northern Technical University, Engineering Technical College, Mosul, Iraq. \\ ${ }^{b}$ Middle Technical University, AL-Suwaira Technical Institute, Baghdad, Iraq.
}

Received: October 10, 2021; Revised: February 11, 2022; Accepted: February 13, 2022.

\begin{abstract}
Nanocoatings thin films are layers deposited to improve required properties and corrosion resistance as a major objective for materials that are used for various biomedical applications such as biosensors. In this study, Gold ( $\mathrm{Au}$ ) thin films with $50 \mathrm{~nm}$ and $100 \mathrm{~nm}$ have been synthesized on Ni-Cr-Mo alloys by magnetron sputtering deposition technique. X-Ray diffraction (XRD), Atomic Force Microscopy (AFM), and Energy-dispersive X-Ray spectroscopy /Scanning Electron Microscopy (EDS/SEM ) have been used to distinguish the surfaces morphology. The results showed that there is no defects or micro-cracks with a uniform and homogenous film. It has spherical nanoparticles diameter morphology with 200-400 nm shaped to fine aggregation. The roughness average (Ra) decreased from $3.91 \mathrm{~nm}$ for $50 \mathrm{~nm}$ films to $3.70 \mathrm{~nm}$ for $100 \mathrm{~nm}$ films with FCC crystal structure (111) for gold thin films. In vivo, after $50 \mathrm{~nm}$ and $100 \mathrm{~nm}$ nanocoated thin film by gold, a significant improvement in the localized corrosion resistance has been obtained in artificial saliva corrosive media at $37^{\circ} \mathrm{C}$ compared with the uncoated surface.
\end{abstract}

Keywords: Corrosion resistance, sputtering deposition process, gold thin films, $\mathrm{Ni-Cr}-\mathrm{Mo}$ biomaterial alloy.

\section{Introduction}

Nanotechnology is the branch of applied science that examines materials on a scale of one to one hundred nanometers (nm). Nevertheless, its characterization is still understudied and investigated although it's used in a wide range of medical applications ${ }^{1}$. One of the most important characteristics is its strong corrosion resistance, which has been demanded of metallic alloys used in biomaterials and food containers. Also, this is accomplished by the creation of nanolayers films made mostly of corrosion-resistant materials ${ }^{2}$.

Tanaka et al. ${ }^{3}$ reviewed several novel properties that happen when the dimensions of solid material shrunk to the point of no return comprise tens to a few thousand atoms. Due to their specific electrical and optical properties, nanostructured deposition plays now a crucial role in several science and technology materials. Also, some of them have scattering losses for that used in the plasmatic, biosensor, and practical material applications. Wadullah et al. ${ }^{4}$ investigated the deposition of platinum thin films by sputtering biomaterials alloy substrates with thicknesses of $17 \mathrm{~nm}$ and $34 \mathrm{~nm}$. The results showed an ability to deposit a nanostructured Pt. thin film with defect-free, and improved localized electrochemical corrosion resistance on artificial saliva at $37^{\circ} \mathrm{C}$. Wadullah et al..$^{5}$ used the Atomic Layer Deposition (ALD) technique to describe the deposition of $25 \mathrm{~nm}$ and $50 \mathrm{~nm}$ thin films of Alumina, Titania, and Alumina/ Titania multilayer thin films on Co-Cr alloy (ASTM F75). The results showed homogeneous thin films with no defects or micro cracks. In comparison to $\mathrm{TiO} 2$ and $\mathrm{Al} 2 \mathrm{O} 3 / \mathrm{TiO} 2$,

*e-mail: dr.haitham@ntu.edu.iq
A12O3ALD films had lower surface roughness values and better thin film thickness control. Priyadarshini et al. ${ }^{6}$ clarified that coating the surface of implant alloys increases the corrosion resistance while also improving the biocompatibility. While this method of obtaining alloys limits metalosis (alloying factors migrating into the tissues surrounding the implant) and replacement the elements of cytotoxic with biocompatible under investigation. Jakub et al. ${ }^{7}$ characterized the annealed goldcoated nanolayers at $100^{\circ} \mathrm{C}$ to $300^{\circ} \mathrm{C}$ by sputtering deposition with 10 and $15 \mathrm{~nm}$ thicknesses on poly-tetrafluoroethylene. The surface has been analyzed using AFM, XPS and zeta potential. Carbon pollution has been discovered, as well as the existence of oxidized structures on annealed gold-coated. Maciej et al. ${ }^{8}$ obtained the gold nanocoatings consistency on zirconium oxide plates deposited with a 10-micron thickness of the coating. The results showed that the golden coatings have been of high quality, with high embedded content tolerance and biocompatibility. Faisal et al. ${ }^{9}$ used the electrochemical deposition method to study gold nanostructures on silicon, and the gravity method to calculate the film thickness. Schaub et al. ${ }^{10}$ investigated the effect of heat treatment at $300{ }^{\circ} \mathrm{C}$ and evaporation technique on the glass to cause gold nanolayer with a thickness of $18 \mathrm{~nm}$ and nanocluster coatings. The results showed that the annealing procedure affects the optical properties and function of gold films and that the peak of Plasmon resonance in structures is amplified by increasing the temperature of glass during evaporation, which causes major changes in surface morphology. Wadullah et al. ${ }^{11}$ investigated that the corrosion resistance of implant alloys can be achieved by annealed gold nanocoated with $17 \mathrm{~nm}$ and $34 \mathrm{~nm}$ thickness. 
They concluded that the gold thin films deposited by the sputtering technique have localized corrosion resistance with decreasing hysteric loop compared with uncoated Ni-Cr-Mo alloy. Sudheer et al. ${ }^{12}$ summarized that thermal evaporation can be used to create ultrathin gold of ( 0.7 to $8.4 \mathrm{~nm})$ deposited on the substrate using the technique of sputtering. It was discovered that as the film thickness increases, the size and density of Au nanoparticles (NPs) changes (from 0.7 to $2.8 \mathrm{~nm}$ ). Besides, during solid-state de-wetting and recrystallization of the grains, electron diffraction measurements indicate annealing-induced morphological evolution in the percolated $\mathrm{Au}$ thin films $(3 \mathrm{~nm})$. McCann et al. ${ }^{13}$ deposited the nanoparticles gold film by a pulsed laser deposition on cyclic olefin polymer substrates. This confinement results in the deposition of nanostructured thin films on the substrate, according to the results. Optical spectroscopy revealed plasmatic activity of the resulting thin film, while infrared spectroscopy revealed no noticeable change in polymer surface chemistry as a result of the deposition process. Bai et al. ${ }^{14}$ performed an experimental study to investigate that gold nanoparticles have excellent properties as compared to bulk materials because of their outstanding biocompatibility and surface plasma resonance as unique properties, such as medical imaging and photothermal killing of cancer cells. Another example is the ability to manipulate particle size and shape, as well as antibody conjugation on the surface for selective imaging and photothermal applications. Schmidl et $\mathrm{al}^{15}$ found that laser parameters such as energy density and number of pulses influence the formation of gold nanoparticles on glass substrates induced by UV lasers. Furthermore, as the sputtering power increases, the microstructures and optical properties of the gold layers change. Yanwei and Michael ${ }^{16}$ analyzed porous gold films and provided a brief overview of porous gold film development over the last ten years, including gold film synthesis and applications. Basova et al. ${ }^{17}$ studied the efficiency improvement of orthopaedic surgery and reconstructive surgical implants using nanoparticles metals. Metallic gold and its alloys have been used as implants for decades in dental applications and reconstructive surgery due to their high biocompatibility, chemical inertia, and corrosion tolerance in biological settings.

After a close review of the literary works ${ }^{3,17}$ on the deposition of gold films, showed that the depositions of gold nanostructured materials on different alloys have received a little bit of attention. Furthermore, the study of the literature indicates that few works have been used $\mathrm{Ni}$-Cr-Mo alloy substrate for depositions of gold thin films nanostructure to produce biocorrosion resistant materials for biological, medicinal, and dental applications. For this reason, the primary focusing goal of this paper is to improve the corrosion resistance of Ni-Cr-Mo biomaterial alloys by synthesizing uniform and homogeneous gold Nanocoating thin films with $50 \mathrm{~nm}$ and $100 \mathrm{~nm}$ thickness using the Magnetron sputtering deposition method with pure $\mathrm{Au}$ targets (99.995 per cent).

\section{Materials and Methods}

In this study, Ni-Cr-Mo medical-grade biomaterials alloy specimens and Si-wafers (100) with 10 x $10 \mathrm{~mm}$ dimensions have been used. The surfaces have been prepared, then cleaned with acetone ethanol and deionized water, and finally dried and kept in a glass vacuum container. Table 1 displays the chemical composition of $\mathrm{Ni}-\mathrm{Cr}-\mathrm{Mo}$ alloy substrates.

Magnetron sputtering deposition devices with Targets of pure Au (99.995\%) have been used from Kurt J lesker co./ United States. The graph of calibration has been used to guess the power/time required to deposit a certain thickness of film after the system was optimized with various targets and power at the Missouri-Columbia University, USA. The deposition conditions that have been optimized are $2.8 \times 10^{-7}$ Torr. vacuum base pressure, $2 \mathrm{~nm} / \mathrm{min}$ rate, 20 standard cubic centimeter per minute ( $\mathrm{sscm}$ ) Argon gas, and $4 \mathrm{~T}_{\text {orr }}$ pressure during deposition.

To analyze the gold thin films deposited, a scanning electron microscope (SEM) with a working accelerating voltage from $3.5^{-10} \mathrm{kV}$ has been used at the Ministry of Science and Technology-Baghdad/Iraq. Before uploading the samples to the SEM chamber, conductive carbon was used to protect them on specimen holders. Smart software has been used to monitor the imaging method. AFM has been used at Nanotechnology Center / Technology University - Iraq to demonstrate the roughness of the thin film deposited. Spectroscopic device type TF Probe used with software available for gold film thickness measurement. Philips (general electric diffraction Pw1840,2009) X-Ray Diffraction (XRD) with $\mathrm{Cu}-\mathrm{K}$ radiation at $0.15418 \mathrm{~nm}$ wavelength, $30 \mathrm{~mA}$, $40 \mathrm{Kv} ., 2$ range scan axis, (20-90) deg. start and end degrees, $0.2^{\circ}$ sampling stage, and $3^{\circ}$ min speed. In the Materials Engineering Dept. / University of Tech, an electrochemical corrosion system called a WINKING M Lab 200 Potentiostat from Bank-Electronic has been used. The working electrode is Ni-Cr-Mo alloy, the auxiliary electrode is platinum, and the reference electrode is the electrode of saturated calomel. Electrochemical measurements have been carried out using electrochemical software and a potentiostat with a $0.5 \mathrm{~mA}$. sec-1 rate of a scan. Table 2 shows the artificial saliva used in the procedure. Open circuit potential ( $\left.\mathrm{E}_{\text {o.c.p. }}\right)$, Tafel extrapolation, and cyclic polarization have been investigated in artificial saliva solution at $37^{\circ} \mathrm{C}$. The key results obtained are corrosion potentials ( $\mathrm{E}_{\text {corr. }}$ ), corrosion current density $\left(\mathrm{i}_{\text {corr. }}\right)$, breakdown potential $\left(\mathrm{E}_{\mathrm{b}}\right)$, Tafel slopes, and re-passivation potential $\left(\mathrm{E}_{\text {rep }}\right)$.

\section{Results and Discussion}

The primary goal of this study is to improve the corrosion resistance of Ni-Cr-Mo biomaterial alloys by synthesizing uniform and homogeneous gold Nanocoating thin films with $50 \mathrm{~nm}$ and $100 \mathrm{~nm}$ thickness using the Magnetron sputtering deposition method.

Table 1. Ni-Cr-Mo alloy chemical composition

\begin{tabular}{cccccc}
\hline Element & $\mathrm{Cr}$ & $\mathrm{Mo}$ & $\mathrm{Fe}$ & $\mathrm{Cu}$ & $\mathrm{Ni}$ \\
\hline Weight $\%$ & 20.9 & 9.94 & 2.4 & 0.13 & Bal. \\
\hline
\end{tabular}


Figure 1 shows a micrograph of EDS/SEM at 100nm gold film deposited on Ni-Cr-Mo alloy substrate after annealing at $300{ }^{\circ} \mathrm{C}$ for $1 \mathrm{hr}$. in an argon setting. The results of the EDS image showed that there is a pure Au element for Gold thin film. EDS results registered broad conclusions to assess the density of each element and in this study, Au nanostructured thin films deposited indicators that $\mathrm{Au}$ is a pure element with high density. The SEM morphology of the film resulted demonstrated that the Au nanocoating film is pure, uniform, and free of contamination, defects or micro-cracks. It contains many spherical nanoparticles with diameters ranging from 200 to $400 \mathrm{~nm}$ shaped to fine aggregation. It's also obvious from the photographs in Figure 1 that the Au film lies on a dense and homogenous layer. The film is made up of dense touching grains that

Table 2. Artificial saliva composition ${ }^{18}$

\begin{tabular}{cc}
\hline Reagents & Concentration $(\mathrm{g} / \mathrm{l})$ \\
\hline $\mathrm{CaCl}_{2} \cdot 2 \mathrm{H}_{2} \mathrm{O}$ & 0.906 \\
\hline $\mathrm{KCl}$ & 0.4 \\
\hline $\mathrm{Na}_{2} \mathrm{~S} \cdot 9 \mathrm{H}_{2} \mathrm{O}$ & 0.005 \\
\hline $\mathrm{NaCl}$ & 0.4 \\
\hline $\mathrm{NaH}_{2} \mathrm{PO}_{4} \cdot 2 \mathrm{H}_{2} \mathrm{O}$ & 0.69 \\
\hline Urea & 1 \\
\hline
\end{tabular}

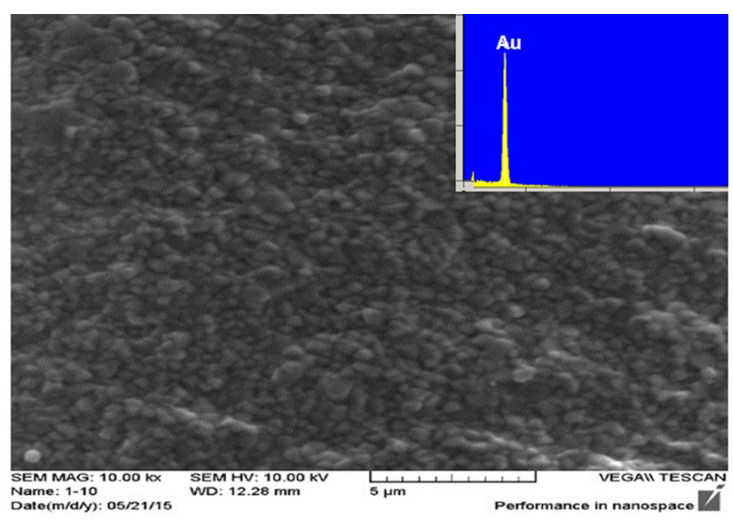

Figure 1. EDS/SEM micrographs of $100 \mathrm{~nm}$ gold thin films at $10.00 \mathrm{kx}$ SEM magnification. are extended horizontally to the surface in this condition. These elongated grains, spherical nanoparticles, have plan diameters mentioned above, with the maximum magnification indicating a range of $10.00 \mathrm{kx}$. The SEM topography results are conforming with the researcher Ruffino et al. ${ }^{19}$.

Figure 2 displays AFM images of nanocoated samples with $50 \mathrm{~nm}$ and $100 \mathrm{~nm}$ gold thin films. The topography showed a slightly different roughness in nanometer scales with different thicknesses, which noted to $3.91 \mathrm{~nm}$ for $50 \mathrm{~nm}$ films and $3.70 \mathrm{~nm}$ for $100 \mathrm{~nm}$ films. This result indicates that the smoothness and homogeneity of the films, as well as the globularity, increased as the Au thickness increases. The results declare that there are variations in roughness before and after sputtering depositions, which offer excellent indicators that the surfaces would get smoother following the thin film depositions procedure. Where the changes in height between valleys and peaks are minor, It has a smooth surface. This is due to the valleys (minimum points) of the surface filling up to become slightly equivalent to the peaks (maximum points) ${ }^{20}$, as a result of the deposition cycles of nanocoatings thin films thickness grow.

Figure 3 and Table 3 show the XRD results of $50 \mathrm{~nm}$ and $100 \mathrm{~nm} \mathrm{Au}$ nanocoated surfaces. The type of material layer with a varying electron density influences changes in reflected intensity. Where each layer's scattering X-ray reflectivity is computed from the sum of individual electron X-ray reflectivity. Also, the period of the oscillations and intensity is determined by the thickness of the film. For that $100 \mathrm{~nm} \mathrm{Au}$ thin film has more intensity/ peak than that of $50 \mathrm{~nm}$. The XRD are in line with the results of researcher Schmidl et al. ${ }^{15}$.

Comparison of XRD test results (d-spacing) with International Center for Diffraction Data (1997) standards 26-0425 is used and also by using the PCPDFWIN program. The Au polycrystalline structure film was studied as a function of the thin film thickness using conventional scanning methods. At the angle of $81.8,77.5$, $64.5,44.4$, and $38.2^{\circ}$ the scan was performed with a peak center position at [111] for $2 \theta=38.2^{\circ}$ of Au. This result indicates that FCCAu crystalline structure can be correlated with the diffraction peaks (111). Also, by Debye-Scherer Equation 1 estimated the average grain size (D) of a crystalline film.

$$
D=\frac{\gamma}{\sqrt{\beta^{2}+\beta_{\text {std }}^{2} \cos \theta}}
$$

where X-Ray radiation wavelength $(\lambda)$ is equal to $0.154 \mathrm{~nm}$. The diffraction angle $(\theta)$, the full width of half maximum
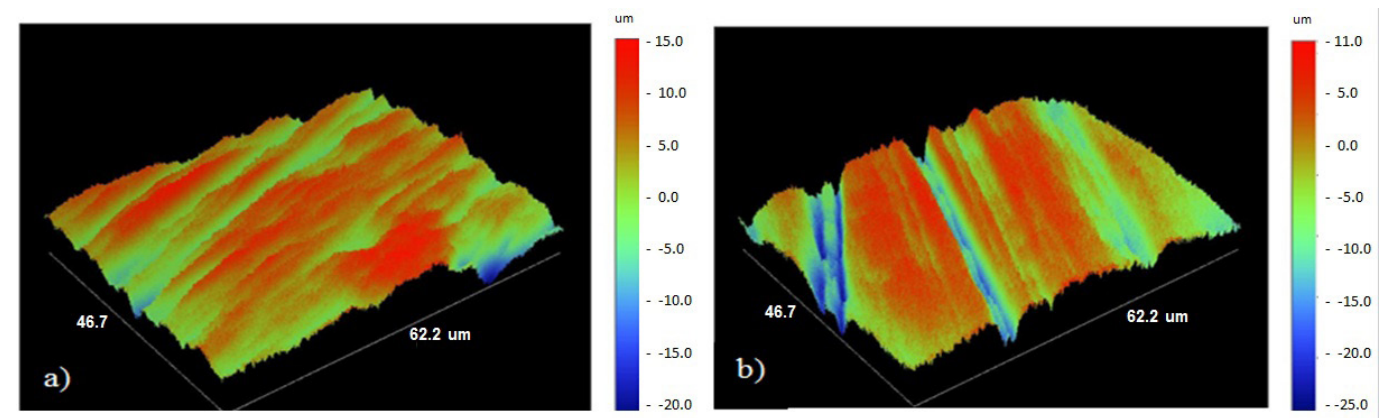

Figure 2. Non-contact AFM images results of gold films in two dimensions; a) nanocoated with $50 \mathrm{~nm}$, and b) nanocoated with $100 \mathrm{~nm}$. 


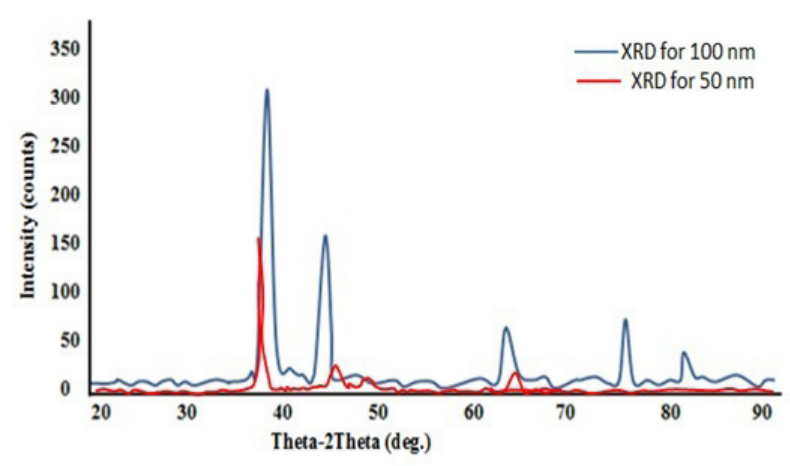

Figure 3. XRD results of the gold films.

Table 3. XRD results of $100 \mathrm{~nm}$ Au thin films.

\begin{tabular}{cccc}
\hline 2 Theta (deg.) & $\mathrm{d}_{\text {standard }}\left(\mathrm{A}^{\circ}\right)$ & $\mathrm{d}_{\text {measured }}\left(\mathrm{A}^{\circ}\right)$ & $\mathrm{hkl}$ \\
\hline 81.8 & 1.177 & 1.175 & 222 \\
\hline 77.5 & 1.23 & 1.22 & 311 \\
\hline 64.5 & 1.442 & 1.430 & 220 \\
\hline 44.4 & 2.039 & 2.00 & 200 \\
\hline 38.20 & 2.355 & 2.345 & 111 \\
\hline
\end{tabular}

Table 4. Parameters of Electrochemical corrosion results.

\begin{tabular}{cccc}
\hline Parameters of Corrosion & Uncoated Ni-Cr-Mo alloy & $\begin{array}{c}\text { Nanocoated Ni-Cr-Mo alloy } \\
\text { with 50nm of Au }\end{array}$ & $\begin{array}{c}\text { Nanocoated Ni-Cr-Mo alloy } \\
\text { with 100nm of Au }\end{array}$ \\
\hline $\mathrm{E}_{\text {o.c.p }}(\mathrm{mV})$ & -675 & -123 & -88 \\
\hline $\mathrm{i}$ corr $\left(\mu \mathrm{A} . \mathrm{cm}^{-2}\right)$ & 597 & 203 & 178 \\
\hline $\mathrm{E}$ corr $(\mathrm{mV})$ & -938 & -892 & -534 \\
\hline$-\mathrm{a}(\mathrm{mV} / \mathrm{Dec})$. & -811 & -582 & -498 \\
\hline$+\mathrm{b}(\mathrm{mV} / \mathrm{Dec})$. & +2586 & +612 & +532 \\
\hline $\left.\mathrm{E}_{\text {b. }} \mathrm{mV}\right)$ & +1500 & +1500 & +1500 \\
\hline $\left.\mathrm{E}_{\text {rep. }} \mathrm{mV}\right)$ & +1350 & +850 & No \\
\hline
\end{tabular}

peak $(\beta)$, and the instrument broadening measured with a single-crystal standard $(\beta \mathrm{std})$ are equal to 0.131 .

In artificial saliva at $37^{\circ} \mathrm{C}$, the electrochemical corrosion results for nanocoated and uncoated samples by 50 and $100 \mathrm{~nm}$ thin films of gold are shown in Table 4 and Figures 4-6. The E o.c.p of the uncoated sample was $(-675 \mathrm{mV})$, but it shifted to a more noble number after nanocoating. It indicates an increase in stability to $(-123 \mathrm{mV})$ for $50 \mathrm{~nm}$ and $(-88 \mathrm{mV})$ for $100 \mathrm{~nm}$ thin film of Au. Uncoated and nanocoated sample with $100 \mathrm{~nm}$ thin film of gold has corrosion current densities $\mathrm{i}_{\text {corr. }}$ of $597 \mathrm{~A} . \mathrm{cm}^{-1}$ and $178 \mathrm{~A} . \mathrm{cm}^{-2}$, respectively. The stability of gold in electrochemical corrosion reactions, which protects the surfaces from corrosion, is responsible for the improved corrosion resistance of nanocoated samples by the film.

The $\mathrm{E}_{\text {corr }}$ of nanocoated samples is higher than that of uncoated samples, indicating that the gold film has a low proclivity for corrosion. For localized corrosion analysis of active-passive metals, $\mathrm{E}_{\mathrm{b}}$ and $\mathrm{E}_{\text {rep }}$. are used. Although the $\mathrm{E}_{\mathrm{b}}$. of nanocoated and uncoated alloys is the same value $(+1500 \mathrm{mV})$, no E rep. value exists for gold nanocoated compared to uncoated alloy. It means greater localized corrosion resistance and the absence of corrosion pits. Furthermore, as shown in the cyclic polarization results, the hysteresis loop of nanocoated samples with $100 \mathrm{~nm}$ of the gold thin film decreases compared to coated with $50 \mathrm{~nm}$ gold thin film and uncoated alloy. Higher resistance to corrosive attack and obtained a greater capacity of re-passivation of Au nanocoating thin film is due to the stability, homogeneity, and lower roughness ${ }^{19}$ of $\mathrm{Au}$ thin film, furthermore to no defects or micro cracks. Coatings create a barrier for surface protection, with the metal surface becoming denser and more protective as the process progresses as confirmed by researchers ${ }^{21}$.

The corrosion rates (mpy) are calculated from the corrosion current density according to ASTM G 102 by using the equation;

$$
\text { Corrosion Rate }(\text { mpy })=0.13 * \text { icorr } *\left[\frac{e . w}{\rho}\right]
$$

where; $i$ corr. is corrosion current density $\left(\mu \mathrm{A} . \mathrm{cm}^{-2}\right)$, e.w is equivalent weight $(\mathrm{g}) ; 22.98 \mathrm{~g}$ for $\mathrm{Co}-28 \mathrm{Cr}-6 \mathrm{Mo}$ alloy, and $\rho$ is the density $\left(\mathrm{g} / \mathrm{cm}^{3}\right) ; 8.9 \mathrm{~g} . \mathrm{cm}^{-3}$ for Co-28Cr-6Mo alloy 

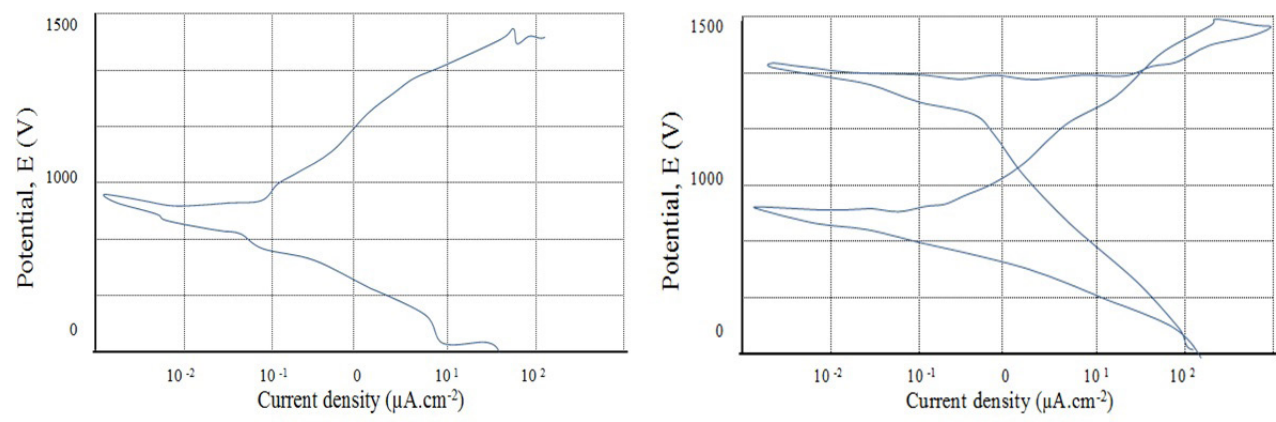

Figure 4. Tafel and Cyclic polarization results of uncoated sample.
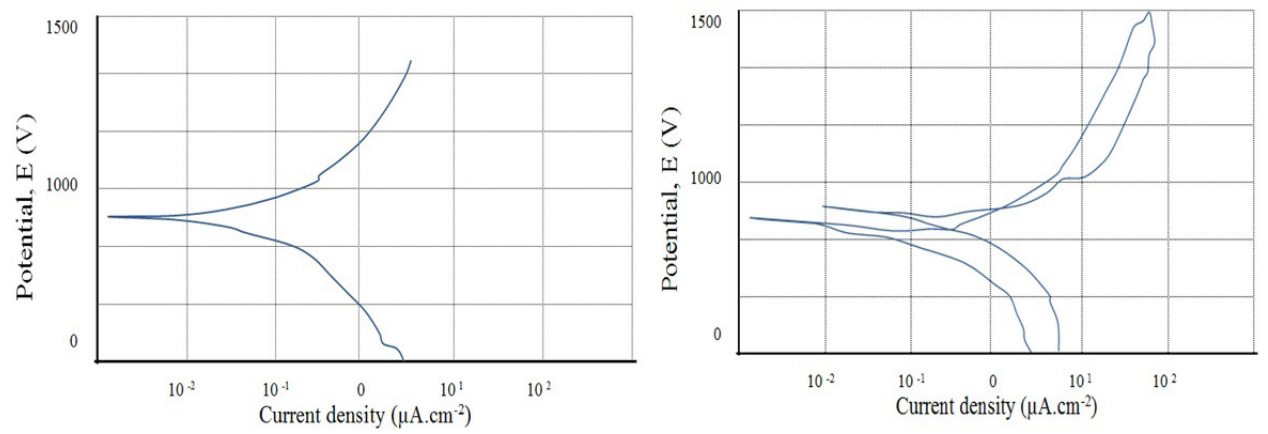

Figure 5. Tafel and Cyclic polarization results of nanocoated with $50 \mathrm{~nm}$ gold thin film.
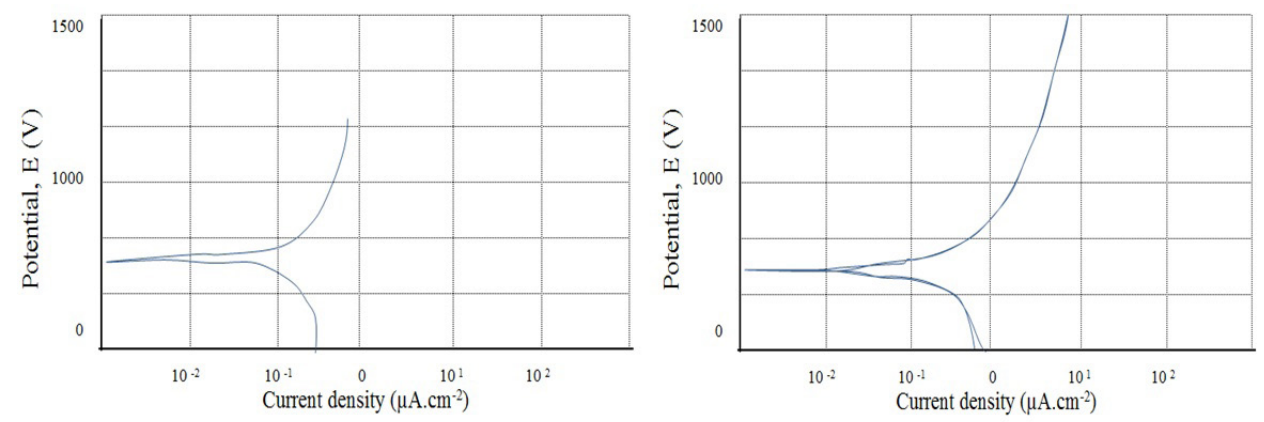

Figure 6. Tafel and Cyclic polarization results of nanocoated with $100 \mathrm{~nm}$ gold thin film.

\section{Conclusions}

The current work has been aimed to increase the corrosion resistance of $\mathrm{Ni}-\mathrm{Cr}-\mathrm{Mo}$ biomaterials alloys nanocoated by the gold thin film with $50 \mathrm{~nm}$ and $100 \mathrm{~nm}$ synthesized by a magnetron sputtering deposition method. The deposition conditions have been optimized by pure Au targets (99.995\%) at $2.8 \times 10-7$ Torr vacuum base pressure, $2 \mathrm{~nm} / \mathrm{min}$ rate, 20 standard cubic centimeter per minute $(\mathrm{sscm})$ Argon steam, and 4 Torr pressure. The XRD, AFM, EDS/SEM, and electrochemical corrosion resistance on artificial saliva at $37{ }^{\circ} \mathrm{C}$ as a biological corrosive medium have been used for uncoated and nanocoated alloys. The following findings can be drawn from this research:

1. EDS/SEM demonstrated that the Au nanocoating is a pure film, uniform, homogenous, and free of contamination, defects or micro-cracks. It contains many spherical nanoparticles with diameters ranging from 200 to $400 \mathrm{~nm}$ shaped to fine aggregation. 
2. XRD analyses revealed pure and crystal FCC structure (111) of Au thin film.

3. AFM exposed an ultra-thin film of Au with decreased roughness from $3.91 \mathrm{~nm}$ to $3.70 \mathrm{~nm}$ after increases the film thickness from $50 \mathrm{~nm}$ to $100 \mathrm{~nm}$ respectively.

4. A major improvement in the localized corrosion resistance have been obtained after $50 \mathrm{~nm}$ and 100 $\mathrm{nm}$ of Au nanocoated on Ni-Cr-Mo alloy compared with uncoated alloy in artificial saliva at $37{ }^{\circ} \mathrm{C}$ with no $\mathrm{E}_{\text {rep }}$. value and a decreases in the hysteric loop. The sputtering deposition technique is an impending nanocoating method to deposit Au thin film on Ni-Cr-Mo sample with superior structure and properties for biomedical applications

\section{Acknowledgement}

We'd like to express our gratitude to the Engineering Technical College- Mosul / Northern Technical University, and The Center of Nanotechnology and Materials Engineering Department at the University of Technology - Baghdad, Iraq for their support to demonstrate this work.

\section{References}

1. Wadullah HM, Sultan SM, Ali OM. Electrochemical Corrosion resistance and in vivo bioactivity of Nickel, Silver and Cobalt nanoparticles materials for medical applications. J Mech Eng Res Dev. 2021;44(4):362-7.

2. Díaz-Elizondo JA, Díaz-Guillén JC, Rodríguez-Rosales NA, Gutiérrez EEG, Ochoa-Hernández G, Mancillas-Salas $\mathrm{S}$, et al. Corrosion resistant CrNX Nanolayers obtained by low temperature ion nitriding of hard chromium coated AISI 1045 steel. Mater Res. 2021;24(4):e20210025. http://dx.doi. org/10.1590/1980-5373-mr-2021-0025.

3. Tanaka M, Saito S, Kita R, Jang J, Choi Y, Choi J, et al. Arraybased screening of silver nanoparticle mineralization peptides. Int J Mol Sci. 2020;21(7):2377. http://dx.doi.org/10.3390/ ijms21072377.

4. Wadullah HM, Abbass MK, Ajeel SA, Hussein MY. Evaluation the corrosion resistance of Pt. thin films for medical applications. AIP Conf Proc. 2020;2213:020319. http://dx.doi. org/10.1063/5.0000444.

5. Wadullah HM, Ajeel SA, Abbass MK. Synthesis and characterization of nanocoatings thin films by atomic layer deposition for medical applications. IOP Conf Ser Mater Sci Eng. 2019;518:032057. http://dx.doi.org/10.1088/1757-899X/518/3/032057.

6. Priyadarshini B, Rama M, Chetan, Vijayalakshmi U. Bioactive coating as a surface modification technique for biocompatible metallic implants: a review. Journal of Asian Ceramic Societies. 2019;7(4):397-406. http://dx.doi.org/10.1080/21870764.2019 .1669861 .

7. Jakub S, Robert K, Zdeňka K, Vladimír H, Václav Š. Annealing of gold nanostructures sputtered on polytetrafluoroethylene. Nanoscale Res Lett. 2011;6(1):588.
8. Maciej B, Maciej H, Dariusz J. Analysis of ceramic implants surface with golden nano-layer. J Metal Czech Republic. 2012;23:5

9. Faisal A-QD, Lafta SH. Investigation of gold nanostructures on silicon using electrochemical deposition method. J AlNahrain Univ. 2013;16(4):134-40. http://dx.doi.org/10.22401/ JNUS.16.4.15.

10. Schaub A, Slepička P, Kašpárková I, Malinský P, Macková A, Švorčík V. Gold nanolayer and nanocluster coatings induced by heat treatment and evaporation technique. Nanoscale Res Lett. 2013;8(1):249. http://dx.doi.org/10.1186/1556-276X-8-249.

11. Wadullah HM, Abbass MK, Ajeel SA. Corrosion of gold thin films deposited by sputtering deposition method. Eng Tech Journal. 2015;6:1145-53.

12. Sudheer, Mondal P, Rai VN, Srivastava AK. A study of growth and thermal dewetting behavior of ultra-thin gold films using transmission electron microscopy. AIP Adv. 2017;7(7):075303. http://dx.doi.org/10.1063/1.4989823.

13. McCann R, Hughes C, Bagga K, Stalcup A, Vázquez M, Brabazon D. Pulsed laser deposition of plasmonic nanostructured gold on flexible transparent polymer at atmospheric pressure. J Phys D Appl Phys. 2017;50(24):245303. http://dx.doi.org/10.1088/13616463/aa7193.

14. Bai X, Wang Y, Song Z, Feng Y, Chen Y, Zhang D, et al. The basic properties of gold nanoparticles and their applications in tumor diagnosis and treatment. Int J Mol Sci. 2020;21(7):2480. http://dx.doi.org/10.3390/ijms21072480.

15. Schmidl G, Raugust M, Dellith J, Bochmann A, Schmidl F, Plentz J. UV laser induced gold nanoparticle fabrication dependent on initial film properties. Opt Mater J. 2020;99:109592. http:// dx.doi.org/10.1016/j.optmat.2019.109592.

16. Yanwei W, Michael S. Integration of 3D Hydrodynamic focused microreactor with microfluidic chemiluminescence sensing for online synthesis and catalytical characterization of gold nanoparticles. Sensors J. 2021;21(7):2290.

17. Basova TV, Vikulova ES, Dorovskikh SI, Hassan A, Morozova NB. The use of noble metal coatings and nanoparticles for the modification of medical implant materials. Mater Des. 2021;204:109672. http://dx.doi.org/10.1016/j. matdes.2021.109672.

18. Wadullah HM, Ajeel SA, Abbass MK, Hussein MY. Corrosion of platinum nanocoatings thin films deposited by Sputtering Deposition Method for medical applications. IACSIT Int J Eng Technol. 2018;7(4):63-6.

19. Ruffino F, Grimaldi MG. Morphological characteristics of Au films deposited on Ti: a combined SEM-AFM study. Coatings. 2018;8(4):121. http://dx.doi.org/10.3390/coatings8040121.

20. Marques FM, Rocha AS, Santos GR, Wolfart M Jr, Costa RC, Ferreira JZ. The influence of surface condition on the electrochemical properties of ASTM F138 steel for biomedical applications. Mater Res. 2021;24(3):e20200062. http://dx.doi. org/10.1590/1980-5373-mr-2020-0062.

21. Leoni GB, Freitas DS, Gomes JAPC, Brasil SLDC. Evaluation of structure, heterogeneities, thickness and corrosion protection of electrodeposited sol-gel superhydrophobic coatings. Mater Res. 2022;25(Suppl.1):e20210460. http://dx.doi.org/10.1590/19805373-mr-2021-0460. 